\title{
ВMJ Global Health Women's health: a new global agenda
}

\author{
Sanne A E Peters, ${ }^{1}$ Mark Woodward, ${ }^{1,2,3}$ Vivekanand Jha, ${ }^{1,4}$ Stephen Kennedy, ${ }^{5}$ \\ Robyn Norton ${ }^{1,2}$
}

To cite: Peters SAE, Woodward M, Jha V, et al. Women's health: a new global agenda. BMJ Global Health 2016;1:e000080. doi:10.1136/bmjgh-2016000080

- Additional material is available. To view please visit the journal (http://dx.doi.org/ 10.1136/bmjgh-2016000080).

Received 4 May 2016 Revised 3 September 2016 Accepted 25 September 2016

\section{Q crossank $^{2}$}

${ }^{1}$ The George Institute for Global Health, University of Oxford, Oxford, UK

${ }^{2}$ The George Institute for Global Health, University of Sydney, Sydney, New South Wales, Australia

${ }^{3}$ Department of

Epidemiology, Johns Hopkins University, Baltimore, Maryland, USA

${ }^{4}$ The George Institute for Global Health, New Delhi, India

${ }^{5}$ Nuffield Department of Obstetrics and Gynaecology, University of Oxford, Oxford, UK

\section{Correspondence to}

Dr Sanne AE Peters;

sanne.peters@

georgeinstitute.ox.ac.uk

\section{ABSTRACT}

Global efforts to improve the health of women largely focus on improving sexual and reproductive health. However, the global burden of disease has changed significantly over the past decades. Currently, the greatest burden of death and disability among women is attributable to non-communicable diseases (NCDs), most notably cardiovascular diseases, cancers, respiratory diseases, diabetes, dementia, depression and musculoskeletal disorders. Hence, to improve the health of women most efficiently, adequate resources need to be allocated to the prevention, management and treatment of NCDs in women. Such an approach could reduce the burden of NCDs among women and also has the potential to improve women's sexual and reproductive health, which commonly shares similar behavioural, biological, social and cultural risk factors. Historically, most medical research was conducted in men and the findings from such studies were assumed to be equally applicable to women. Sex differences and gender disparities in health and disease have therefore long been unknown and/or ignored. Since the number of women in studies is increasing, evidence for clinically meaningful differences between men and women across all areas of health and disease has emerged. Systematic evaluation of such differences between men and women could improve the understanding of diseases, as well as inform health practitioners and policymakers in optimising preventive strategies to reduce the global burden of disease more efficiently in women and men.

\section{INTRODUCTION}

The global burden of disease among women has changed significantly over the past decades. Non-communicable diseases (NCDs) are now the leading causes of death and disability for women in almost all countries of the world. Nearly $80 \%$ of NCDs occur in low-income and middle-income countries (LMICs), and it is particularly in these parts of the world where NCDs are rapidly replacing infectious diseases, maternal and child conditions, and nutritional deficiencies as the leading causes of death and disability.

Despite their obvious and growing significance, NCDs continue to be sidelined as a major concern to the health of women globally. Instead, global efforts to improve the

\section{Key messages}

- Non-communicable diseases (NCDs) are the leading causes of death and disability among women worldwide. The global agenda for the health of women needs to be redefined and broadened to ensure the allocation of adequate resources to:

- Increase awareness, promote research, and implement policies and interventions to prevent, treat and optimise outcomes for NCDs among women;

- Promote a life-course approach to addressing sexual and reproductive health issues, recognising that such an approach has the potential to lead to reductions in sexual and reproductive health conditions and NCDs.

- To design, evaluate and deliver the best healthcare interventions and policies for the prevention and treatment of diseases in women:

- Appropriate numbers of women should be included in scientific studies;

- A systematic approach to the sexdisaggregated collection, analyses and dissemination of healthcare data is needed, as well as sex-disaggregated implementation of results.

- To improve health outcomes in women (and men), so as to ensure a one-third reduction in premature mortality from NCDs by 2030 , as well as mental health and well-being:

- The sex-specific impact of biological, behavioural, social, cultural and economic factors in risk and outcomes for NCDs needs to be further examined;

- Pathways and quality of healthcare for women for the prevention and treatment of NCDs need to be addressed; whether these pathways differ for men and women needs to be examined; and strategies to ensure that women (and men) receive the best available healthcare need to be developed, evaluated and implemented.

health of women have largely focused on improving women's sexual and reproductive health. Partly owing to these efforts, particularly after the introduction of the Millennium Development Goals (MDGs) in 2000 and subsequent actions, the number of maternal deaths has dropped by $44 \%$ from 385 in 1990 
to 216 per 100000 live births in $2015 .{ }^{1}$ While the women's sexual and reproductive health agenda remains unfinished and sustained effort and commitment are needed, more women now die annually from NCDs than from any other cause (figure 1). In 2012, an estimated 18.1 million women died from NCDs, of which $\sim 8.8$ million were due to cardiovascular disease (CVD), 3.5 million to cancers and 1.8 million to respiratory diseases (figure 2). ${ }^{2}$ The global agenda for women's health must, therefore, encompass women's sexual and reproductive health, as well as the leading causes of death and disability for women, especially NCDs.

Despite the importance of NCDs to women's health, medical research on NCDs has generally only involved men. This has occurred in part because of the widely held assumption that the occurrence and outcomes of NCDs, as well as the efficacy of preventative measures, are the same for men and women, and that the findings of studies into disease processes involving only men apply equally to women. There is an increasing notion that this is not the case and our knowledge about disease occurrence and disease outcomes-for men and women-can be improved by undertaking analyses of health data disaggregated by sex and informed by a gender perspective, as well as by including sufficient numbers of women in scientific studies. Hence, to optimise the health of women globally, the women's health agenda must have a broader definition and prioritise a sex-specific and gender-specific approach to the collection and usage of health data.

The recently launched policy paper, 'Women's Health: A New Global Agenda', 3 addresses the above issues, describes current practice and policy and calls for a redefinition and broadening of the women's health agenda so as to prioritise NCDs and ensure systematic sex-specific and gender-specific approaches to the collection, analyses and reporting of health data. A full-text version of the paper can be accessed in the online supplementary appendix. Box 1 describes the commonly used distinction between the terms sex and gender. Here, we provide a summary of the paper's main findings and recommendations.

\section{Box 1 Sex versus gender}

Sex refers to the true biological and physiological differences between men and women, including differences in hormonal profiles and sex organs, which result from a single chromosomal difference between men $(X Y)$ and women $(X X)$. Gender refers to the socially constructed roles, behaviours, activities and attributes that are considered appropriate for men and women, that is, the roles that a given society, or individual, considers as masculine and feminine. Aspects of sex are genetically determined and will not vary substantially between different societies. In contrast, aspects of gender may vary greatly by ethnicity, culture and socioeconomic environment. Sex-specific and gender-specific research addresses how experiences of the same disease vary with respect to biological sex and gender.

\section{Redefining women's health}

Current approaches to improving the health of women do not address those health conditions that are responsible for the greatest burden of ill health, namely NCDs. It also does not fully address the importance of certain reproductive health factors-such as gestational diabetes and pregnancy-induced hypertension-for the health of women in later life. This limits the opportunities to improve the health of the maximum number of women in the most effective ways possible. Moreover, a women's health agenda that focuses almost exclusively on women of childbearing age is discriminatory as it excludes those women who do not have children (either voluntarily or involuntarily) and women who are no longer of reproductive age. A broadened definition of women's health that incorporates a greater focus on NCDs-as well as a lifecourse approach to sexual and reproductive health (SRH) and NCDs-has the potential to lead to greater health benefits for women-and in effect the health of their communities—globally.

\section{Leading causes of death and disability among women}

NCDs are the leading causes of death and disability worldwide and their contribution to the global burden of disease is growing rapidly. In 2013, 7 out of 10 leading causes of death among women were NCDs, compared with 4 out of 10 leading causes of death in 1990. Since 1990, maternal and infant deaths have decreased sharply and neither is ranked in the top 10 causes of death globally. Instead, ischaemic heart disease (IHD) and stroke were the number 1 and 2 leading causes of death for women, followed by chronic obstructive pulmonary disease (COPD), Alzheimer's disease, diabetes, hypertensive heart disease and lung cancer. ${ }^{4}$ Lower respiratory infections, diarrhoeal diseases and HIV/ AIDS were the communicable diseases that completed the top 10 and were ranked at places 3,7 and 8, respectively. Even in LMIC in Africa, NCDs account for an increasing burden of death among women. While infectious diseases, maternal and child conditions, and malnutrition remain a leading cause, NCDs caused a third of all deaths in 2012, compared with a quarter of all deaths in 2000 (figure 1). ${ }^{2}$ Similarly, five of the leading causes of disability-adjusted life years for women across the world in 2013 were NCDs, namely IHD, low back and neck pain, stroke, major depressive disorder, and COPD. Complications arising from preterm birth continue to be included in the top 10 leading causes of disability, ranked at the ninth position. ${ }^{4}$ Lower respiratory infections, diarrhoeal diseases, HIV/AIDS and malaria completed the list of the top 10 leading causes of disability and were ranked at the third, sixth, seventh and eighth positions, respectively.

\section{Current policies and practices}

The United Nation's (UN) MDGs formed a blueprint agreed to by all the world's countries and major development institutions to improve international development 
Global

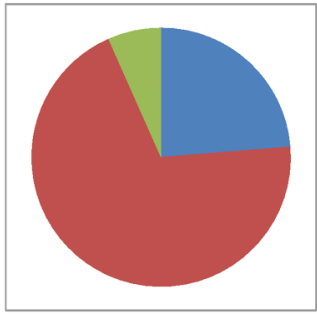

Low- and middle income countries

African Region

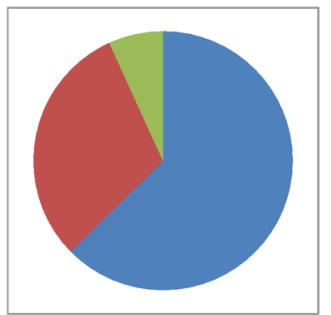

South-East Asia Region

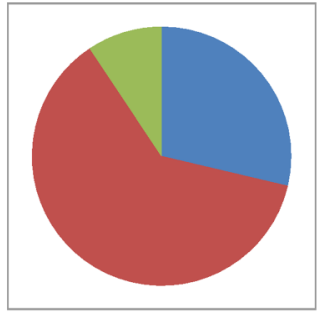

Eastern Mediterranean Region

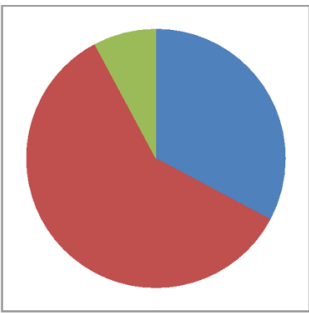

High-income countries

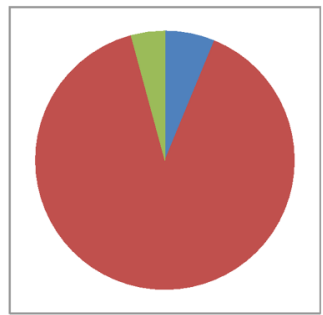

Non-communicable diseases

Communicable diseases

Injuries

Figure 1 Deaths from non-communicable diseases, communicable diseases and injuries among women in 2012, by the World Bank income category and the WHO region. Data were obtained from the Global Health Estimates 2014 Summary Tables. ${ }^{2}$ List of World Bank income categories and WHO regions: high-income countries: Andorra, Antigua and Barbuda, Australia, Austria, Bahamas, Bahrain, Barbados, Belgium, Brunei Darussalam, Canada, Chile, Croatia, Cyprus, the Czech Republic, Denmark, Estonia, Equatorial Guinea, Finland, France, Germany, Greece, Iceland, Ireland, Israel, Italy, Japan, Kuwait, Latvia, Lithuania, Luxembourg, Malta, Monaco, the Netherlands, New Zealand, Norway, Oman, Poland, Portugal, Qatar, Russian Federation, Saint Kitts and Nevis, San Marino, Saudi Arabia, Singapore, Slovakia, Slovenia, South Korea, Spain, Sweden, Switzerland, Trinidad and Tobago, the United Arab Emirates, the UK, the USA, Uruguay; African region: Algeria, Angola, Benin, Botswana, Burkina Faso, Burundi, Cabo Verde, Cameroon, Central African Republic, Chad, Comoros, Congo, Côte d'Ivoire, Democratic Republic of the Congo, Eritrea, Ethiopia, Gabon, Gambia, Ghana, Guinea, Guinea-Bissau, Kenya, Lesotho, Liberia, Madagascar, Malawi, Mali, Mauritania, Mauritius, Mozambique, Namibia, Niger, Nigeria, Rwanda, Sao Tome and Principe, Senegal, Seychelles, Sierra Leone, South Africa, Swaziland, Tanzania, Togo, Uganda, Zambia, Zimbabwe; region of the Americas: Argentina, Belize, Bolivia, Brazil, Colombia, Costa Rica, Cuba, Dominica, Dominican Republic, Ecuador, El Salvador, Grenada, Guatemala, Guyana, Haiti, Honduras, Jamaica, Mexico, Nicaragua, Panama, Paraguay, Peru, Saint Lucia, Saint Vincent and the Grenadines, Suriname, Venezuela; South-East Asia region: Bangladesh, Bhutan, India, Indonesia, Maldives, Myanmar, Nepal, North Korea, Sri Lanka, Thailand, Timor-Leste; European region: Albania, Armenia, Azerbaijan, Belarus, Bosnia and Herzegovina, Bulgaria, Georgia, Hungary, Kazakhstan, Kyrgyzstan, Montenegro, Moldova, Romania, Serbia, Tajikistan, Macedonia, Turkey, Turkmenistan, Ukraine, Uzbekistan; Eastern Mediterranean region: Afghanistan, Djibouti, Egypt, Iran, Iraq, Jordan, Lebanon, Libya, Morocco, Pakistan, Somalia, South Sudan, Sudan, Syria, Tunisia, Yemen; Western Pacific region: Cambodia, China, Cook Islands, Fiji, Kiribati, Lao, Malaysia, Marshall Islands, Micronesia, Mongolia, Nauru, Niue, Palau, Papua New Guinea, Philippines, Samoa, Solomon Islands, Tonga, Tuvalu, Vanuatu, Viet Nam. 
Global
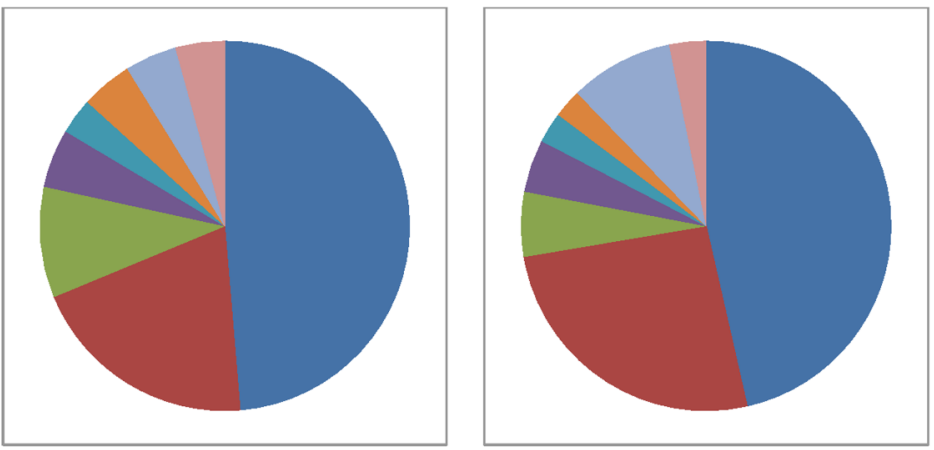

Low- and middle income countries

African Region

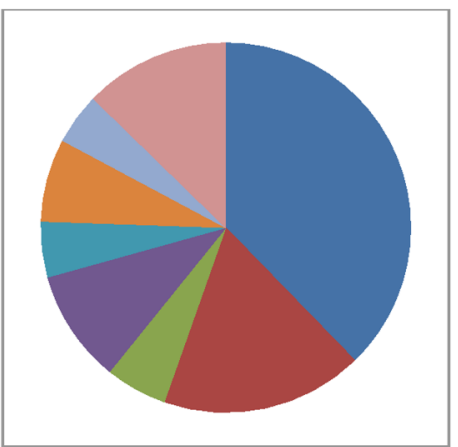

South-East Asia Region

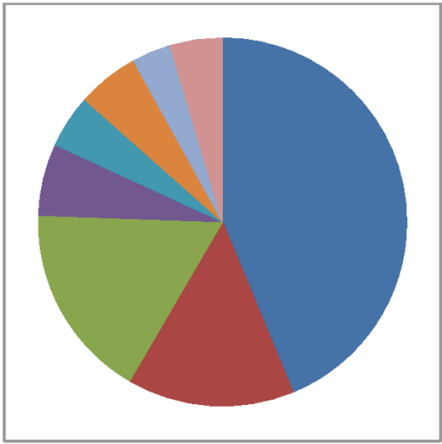

Eastern Mediterranean Region
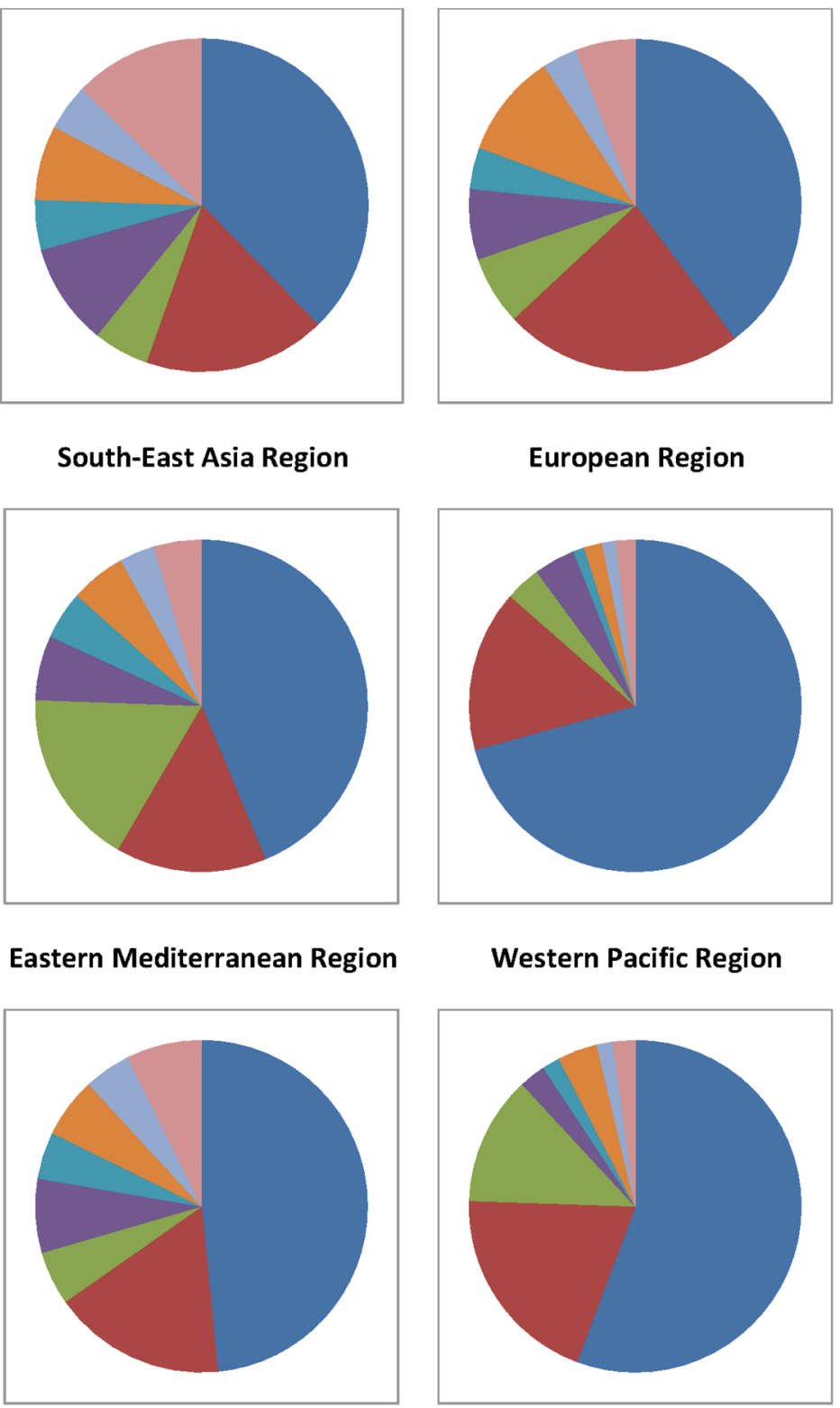

European Region

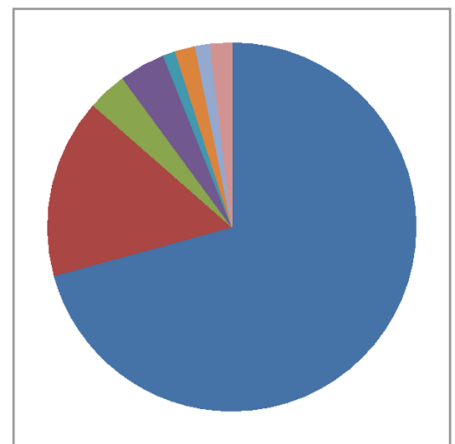

Western Pacific Region

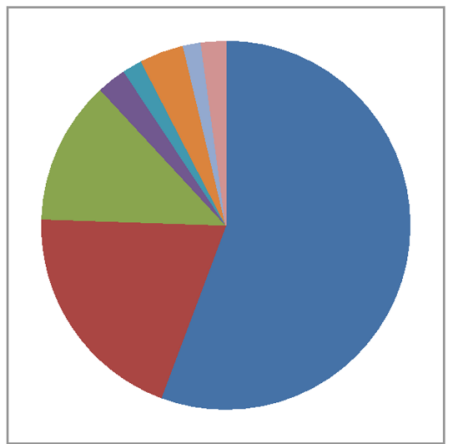

High-income countries

Cardiovascular diseases

Neoplasms

Respiratory diseases

Digestive diseases

Genitourinary diseases

Diabetes mellitus

Neurological conditions

Other

Figure 2 Deaths from non-communicable diseases among women in 2012, by cause, World Bank income category, and WHO region. Data were obtained from the Global Health Estimates 2014 Summary Tables ${ }^{2}$ World Bank income category and WHO regions as in figure 1. 
and meet the need of the poorest. Improving maternal health is the fifth MDG and targeted to reduce maternal mortality by $75 \%$ from 1990 to 2015 , primarily by improving access to reproductive health. ${ }^{1}$

Progress in reducing the number of maternal deaths was initially limited in many countries. Therefore, the UN Secretary-General, Ban Ki-moon, launched the Global Strategy for Women's and Children's Health in 2010. The Global Strategy called for intensified international and national action to address the major health challenges facing women and children. ${ }^{5}$ It led to the establishment of the Every Woman Every Child movement, which presents a roadmap on ending all preventable deaths among women and children and adolescents. ${ }^{6}$ It also led to the establishment of the Global Financing Facility, the key financing platform of the Every Woman Every Child movement. ${ }^{7}$

In September 2015, the updated Global Strategy for Women's, Children's and Adolescents' Health (20162030) was launched by the UN Secretary-General, in partnership with the WHO. ${ }^{8}$ The Strategy comprises new and refreshed efforts to improve the health and end all preventable deaths of women, children and adolescents by 2030. In line with the Sustainable Development Goals (SDGs), a commitment was made to a one-third reduction in premature mortality from NCDs. ${ }^{9}$ Concurrent with the release of the updated Global Strategy, the UN General Assembly hosted the 'Global Leaders' Meeting on 'Gender Equality and Women's Empowerment: A Commitment to Action'. At this meeting, financial commitments totalling US $\$ 25$ billion were made and substantial political support was expressed. ${ }^{10}$ However, women's sexual and reproductive health remained a common theme of the meeting, with the occasional reference to violence against women and female genital mutilation. A full appreciation of women's health, in its broader sense, was lacking.

In contrast, the WHO has expressed support to the Global Strategy. However, the WHO also highlights the changing nature of the health problems facing women, especially in LMICs. It therefore emphasises the need to move the women's health agenda beyond a primary focus on reproductive health issues and to take a lifecourse approach to women's health. ${ }^{11}$ In particular, the WHO stresses the inter-relationships between maternal health problems, such as gestational diabetes and pregnancy-induced hypertension, and the risk of NCDs in later life and emphasises the potential value of integrating maternal health services with those that identify and manage women at high risk of NCDs. In 2015, the report by the Lancet Commission on Women and Health's, 'Women and Health: the key for sustainable development' echoed many of the calls by the WHO. The Lancet Commission highlighted that the global response to NCDs was not proportionate to their burden among women and stressed the need for concerted efforts to integrate maternal and child health services with those that identify and manage women at high risk of NCDs in later life. ${ }^{12}$

SDG 3 sets several targets for 'ensuring healthy lives and promoting the well-being for all at all ages', including further reductions in maternal mortality and a one-third reduction in premature mortality from NCDs by $2030 .{ }^{9}$ SDG 5 sets targets for 'achieving gender equality and empower all women and girls'. Gender equality and women's empowerment have the potential to improve women's health through better access to healthcare and reduced risks imposed by traditional social roles and constructs, such as greater exposure to smoke from biomass fuels used for cooking. Hence, while awareness about the significance of NCDs and strategies to reduce them are growing and are already high in high-income countries (HICs), sex-specific elements of risk awareness, access and quality of care are not well recognised and should be on global public health agendas, particularly in LMICs.

\section{Sex-specific and gender-specific health research}

Sex differences and gender disparities in the occurrence, management and outcomes of chronic health conditions have long been under-recognised. Health research in CVD, for instance, was once predominantly conducted in men and it was assumed that medical practices based on research findings involving men only were equally relevant for women. ${ }^{13}$ This approach limits the generalisability of research findings and their applicability to clinical practice, in particular for women but also for men. A growing body of evidence from studies including both men and women suggests that such research is prejudiced, as well as potentially harmful for women. For example, between 1997 and 2000, 8 of 10 drugs withdrawn from the US market because of side effects were withdrawn because of greater health risks for women than for men. ${ }^{14}$ Moreover, research on cardiovascular conditions increasingly demonstrates that there are clinically meaningful sex differences and gender disparities in the occurrence, management and outcomes of CVD. ${ }^{15} 16$ In what follows, we highlight some recent findings relevant to sex differences in the area of CVDs. Most of these findings come from studies in HICs. The evidence from LMICs and for other NCDs, including for some cancers, osteoporosis and other conditions that are generally more common in women than in men, is much scarcer.

\section{Sex differences in CVD}

CVD is still widely considered as a male disease, an assumption that stems largely from observations that CVD in women develops later in life than in men, and the historical misperception that CVD among women may not be as serious as it is in men. This is despite the fact that CVD causes more deaths in women than any other disease in almost all countries in the world. Awareness of the importance of CVD in women has increased substantially in HICs. However, there remains a substantial gap between the perceived and actual risk 
of CVD in women, and few women see it as a threat to their health. ${ }^{17}$

Recent evidence has demonstrated that are clinically relevant differences between men and women in the occurrence of the various manifestations of CVD. ${ }^{18} 19$ Men tend to develop CVD at a younger age and, as such, have higher rates of IHD than women. In contrast, women are at a higher risk of having a stroke, which occurs more often at an older age. Healthcare services for the management of established CVD are also delivered differently between sexes. This is despite evidence that, generally speaking, preventative therapies are equally effective in women as in men. For example, women are less likely to receive pharmacological treatment for CVD risk factors than men and are also less likely to be referred for diagnostic and therapeutic procedures. $^{20-22}$ Suboptimal access to healthcare services could delay the diagnosis and treatment of CVD and may lead to worse prognosis and outcomes for women with CVD.

In addition to differences in the secondary prevention of CVD, there is now convincing evidence that the effects of some risk factors, such as smoking and diabetes, on the risk of CVD are disproportionally stronger in women than in men (figure 3). ${ }^{23-25}$ In contrast, the impact of excess weight, high blood pressure and elevated lipid levels on CVD outcomes appears to be similar between sexes. The mechanisms underpinning the differences in the relationship between smoking and diabetes and CVD outcomes are not fully understood. However, it is most likely that sex-specific biological factors, such as hormones and differences in body shape, as well as behavioural, social and cultural factors related to risk behaviours and gender disparities in access and usage of health services are involved.
Recently, marked progress has been made in the involvement of women in large-scale population studies and clinical trials and the conduct and report of sexspecific analyses. Moreover, the American Heart Association has been at the forefront of the development of clinical guidelines specific to the cardiovascular health of women. ${ }^{17} 26$ However, several gaps in our understanding of sex differences or gender disparities in health outcomes remain. Systematic examination of sex differences and/or gender disparities in the presentation and outcomes of diseases, and understanding of their underlying mechanisms, are therefore needed. Such research makes optimal use of the data as they are available and have the potential to contribute significantly to the development and implementation of evidence-based efforts to improving the health of women (and men) worldwide.

\section{Current policies and practices to sex-disaggregated health research}

The Fourth World Conference on Women in 1995 was a major step forward in the promotion of sexdisaggregated health research. At this meeting, the Beijing Declaration and Platform of Action was developed, a progressive blueprint for advancing women's rights, gender equality and the empowerment of all women. ${ }^{27}$ As a defining framework for change, the Platform for Action made comprehensive commitments under 12 critical areas of concern for women and girls. In the domain of health, the Platform for Action underscored the need to systematically collect and analyse health data by sex. Many governments, UN agencies and non-governmental organisations have subsequently committed to gender mainstreaming, that is, the evaluation of how any planned policy action
Figure 3 Ratio of relative risks of heart disease and stroke associated with higher blood pressure, smoking, type I and II diabetes, and higher cholesterol in women compared with men. Women-to-men ratio of relative risks (RRs) of heart disease and stroke for (1) those with a $10 \mathrm{~mm} \mathrm{Hg}$ higher value of systolic blood pressure; (2) smoking compared with not; (3) type I diabetes compared with not; (4) type II diabetes compared with not; (5) those with a $1 \mathrm{mmol} / \mathrm{L}$ higher value of total cholesterol. Ninety-five per cent Cls are shown as horizontal lines around the estimates on the graph.
Ratio of $\operatorname{RR}(95 \% \mathrm{Cl})$

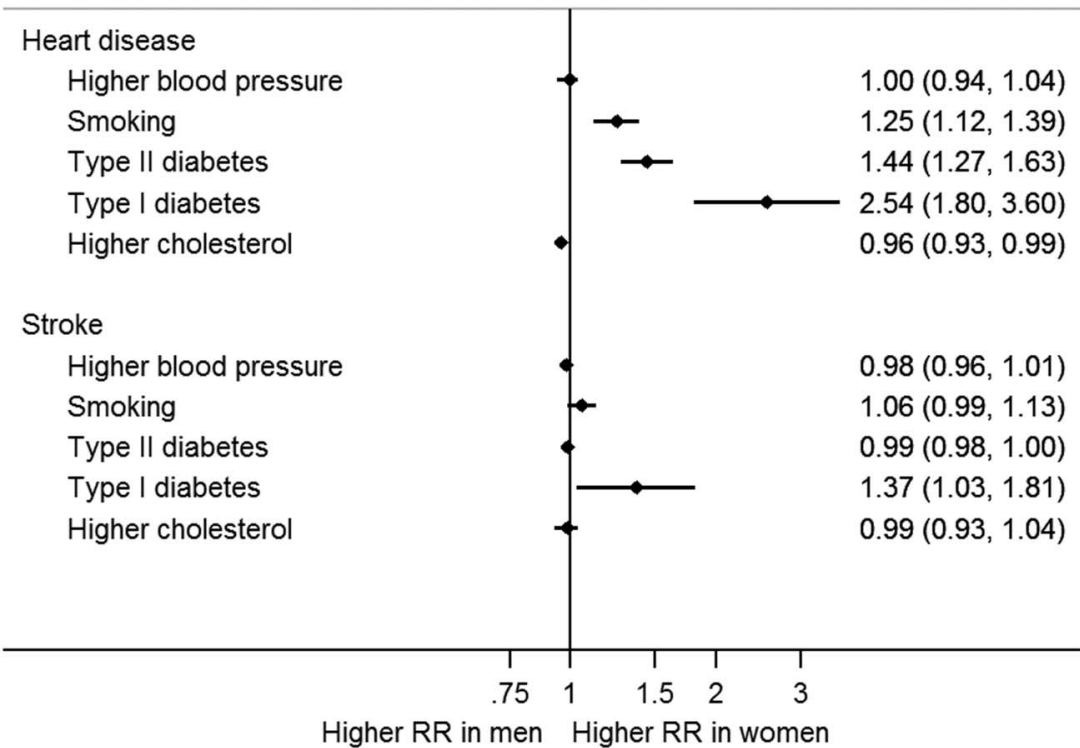


might have different implications for women and men, as a strategy towards achieving gender equality.

The Roadmap for Action, 2014-2019, produced and endorsed by the WHO, also sets to ensure the integration of equity, human rights, gender and social determinants across all WHO programmes and in all Member States. ${ }^{28}$ The promotion of sex-disaggregated data analysis and health inequality monitoring is one of the three key directions of this report.

Gender-sensitive and sex-disaggregated data are also essential to the attainment of all SDGs, as described in detail in the role of gender-based innovations for the UN SDG. ${ }^{29}$ Also, in the advice paper 'Gendered Research and Innovation', the League of European Research Universities (LERU) builds the case for integrating sex and gender analysis into the research process. It provides illustrative case studies of how a gender-specific approach to science has led to new insights and knowledge. $^{30}$ The paper encourages members of LERU and other universities to engage with governments, funding agencies and peer-reviewed journals to highlight the importance of gender-based research and innovation, so as to ensure that sufficient funds and efforts are being allocated.

Similarly, policies have been developed in the Europe and North America to incorporate sex and gender systematically into the conduct of research. Major science funding bodies, such as Horizon 2020 in the European Union (EU), now request that researchers explicitly identify how sex-specific and gender-specific issues will inform and influence their research and, where relevant, show that their studies have been designed to facilitate such analyses. Several medical journals, including The Lancet, have developed policies requiring that women are routinely included in clinical trials and that authors report sex-specific analyses in their publications. Moreover, a global group of academics and practitioners recently published a report in which they argued for gender-sensitive research impact assessment as a means to improve gender equity in science policy and practice. $^{31}$

However, there is still some way to go to ensure that these recommendations are implemented. The 2009 European Commission report on Access to Healthcare and Long-Term Care concluded that little is known about gender disparities in access to, and usage of, healthcare services in the $\mathrm{EU},{ }^{32}$ or the impact of these differences on service delivery. Additionally, the report stated that sex-based and gender-based health research is needed to increase knowledge about the complex ways in which biological, social, cultural and environmental factors interact to affect the health of women and men. A recent US publication showed that the majority of applications for high-risk cardiovascular devices to the US Food and Drug Administration (FDA) were lacking sex-specific data and that women were still under-represented in clinical trials. ${ }^{33}$ The 2016 Sex and Gender Equity in Research (SAGER) guidelines are the next step forward in the need for a more systematic approach to sex-disaggregated health research. The guidelines provide comprehensive guidance to authors and journal editors in integrating assessment of sex and gender into all in study design, data analyses, results and interpretation of findings across disciplines. ${ }^{34}$ Sustained and universal commitment is clearly needed to translate policy into practice.

\section{CONCLUSION}

The global agenda for women's health needs to be broadened and redefined and a sex-disaggregated approach to health research and policy is required. While NCDs are the leading causes of death and disability among women globally, they remain insufficiently addressed in global strategies to improve the health of women. Adequate resources and concerted efforts at local, national and international levels are required to improve NCD outcomes among women throughout the life course. Moreover, to design, evaluate and deliver the best healthcare interventions and policies for the prevention and treatment of diseases, sex differences need to be routinely considered across all areas of health and medicine. A life-course approach to NCDs, together with the sex-disaggregated collection and use of healthcare data, informed by a gender perspective, has the potential to make important contributions to the health of women (and men) globally.

\section{Handling editor Seye Abimbola}

Twitter Follow Vivekanand Jha at @vjha126

Contributors SAEP and RN drafted the manuscript. MW, VJ and SK revised the manuscript and provided critical input.

Competing interests None declared.

Provenance and peer review Not commissioned; externally peer reviewed.

Data sharing statement No additional data are available.

Open Access This is an Open Access article distributed in accordance with the Creative Commons Attribution Non Commercial (CC BY-NC 4.0) license, which permits others to distribute, remix, adapt, build upon this work noncommercially, and license their derivative works on different terms, provided the original work is properly cited and the use is non-commercial. See: http:// creativecommons.org/licenses/by-nc/4.0/

\section{REFERENCES}

1. World Health Organization. Health in 2015: from MDGs to SDGs. 2015. http://apps.who.int/iris/bitstream/10665/200009/1/ 9789241565110_eng.pdf?ua=1 (accessed 22 Apr 2016).

2. World Health Organization. Global Health Estimates 2014 Summary Tables. 2014. http://www.who.int/healthinfo/global_burden_disease/ estimates/en/index1.html (accessed 22 Apr 2016).

3. Norton R, Peters S, Jha V, et al. Women's health: a new global agenda. Oxford: Oxford Martin School, 2016.

4. Institute for Health Metrics and Evaluation. The Global Burden of Disease. 2013. http://vizhub.healthdata.org/gbd-compare/\# (accessed 18 Aug 2016).

5. Secretary-General UN. Global strategy for women's and children's health. New York: The Partnership for Maternal, Newborn and Child Health, 2010.

6. Every Women Every Child. Saving lives protecting futures. Progress report on the global strategy for women's and children's health 2010-2015. New York: Every women Every Child, 2015. 
7. Desalegn H, Solberg E, Kim JY. The Global Financing Facility: country investments for every woman, adolescent, and child. Lancet 2015;386:105-6.

8. Every Women Every Child. The global strategy for women's, children's and adolescents' health (2016-2030). New York: Every Women Every Child, 2015.

9. United Nations. Sustainable Development Goals: 17 goals to transform our world. http://www.un.org/sustainabledevelopment/ sustainable-development-goals/ (accessed 22 Apr 2016)

10. United Nations. UN Secretary-General Announces \$25 Billion in Initial Commitments to End Preventable Deaths of Women, Children and Adolescents by 2030. http://www.un.org/sustainabledevelop ment/blog/2015/09/un-secretary-general-announces-25-billion-ininitial-commitments-to-end-preventable-deaths-of-women-childrenand-adolescents-by-2030/ (accessed 22 Apr 2016)

11. World Health Organization. Special theme: women's health beyond reproduction-a new agenda. Bull World Health Organ 2015;91:621-715.

12. Langer A, Meleis A, Knaul FM, et al. Women and health: the key for sustainable development. Lancet 2015;386:1165-210.

13. Melloni C, Berger JS, Wang TY, et al. Representation of women in randomized clinical trials of cardiovascular disease prevention. Circ Cardiovasc Qual Outcomes 2010;3:135-42.

14. US Government Accountability Office. Drug Safety: Most Drugs Withdrawn in Recent Years Had Greater Health Risks for Women. 2001. http://www.gao.gov/new.items/d01286r.pdf

15. Gupta A, Lampropulos JF, Bikdeli B, et al. Most important outcomes research papers on cardiovascular disease in women. Circ Cardiovasc Qual Outcomes 2013;6:e1-7.

16. Mosca L, Barrett-Connor E, Wenger NK. Sex/gender differences in cardiovascular disease prevention: what a difference a decade makes. Circulation 2011;124:2145-54.

17. Mosca L, Benjamin EJ, Berra K, et al. Effectiveness-based guidelines for the prevention of cardiovascular disease in women2011 update: a guideline from the American Heart Association. J Am Coll Cardiol 2011;57:1404-23.

18. Leening MJ, Ferket BS, Steyerberg EW, et al. Sex differences in lifetime risk and first manifestation of cardiovascular disease: prospective population based cohort study. BMJ 2014;349: g5992.

19. George J, Rapsomaniki E, Pujades-Rodriguez M, et al. How does cardiovascular disease first present in women and men? Incidence of 12 cardiovascular diseases in a contemporary cohort of $1,937,360$ People. Circulation 2015;132:1320-8.

20. Anderson RD, Pepine CJ. Gender differences in the treatment for acute myocardial infarction: bias or biology? Circulation 2007;115:823-6.
21. Cabana MD, Kim C. Physician adherence to preventive cardiology guidelines for women. Womens Health Issues 2003;13:142-9.

22. Humphries $\mathrm{KH}, \mathrm{Pu} \mathrm{A}$, Gao M, et al. Angina with "normal" coronary arteries: sex differences in outcomes. Am Heart $J$ 2008;155:375-81.

23. Huxley RR, Woodward M. Cigarette smoking as a risk factor for coronary heart disease in women compared with men: a systematic review and meta-analysis of prospective cohort studies. Lancet 2011;378:1297-305.

24. Peters SA, Huxley RR, Woodward M. Diabetes as risk factor for incident coronary heart disease in women compared with men: a systematic review and meta-analysis of 64 cohorts including 858,507 individuals and 28,203 coronary events. Diabetologia 2014;57:1542-51

25. Peters SA, Huxley RR, Woodward M. Diabetes as a risk factor for stroke in women compared with men: a systematic review and meta-analysis of 64 cohorts, including 775,385 individuals and 12,539 strokes. Lancet 2014;383:1973-80.

26. Regensteiner JG, Golden S, Huebschmann AG, et al. Sex differences in the cardiovascular consequences of diabetes mellitus: a scientific statement from the American Heart Association. Circulation 2015;132:2424-47.

27. Women UN. Beijing Declaration and Platform of Action UN Women. 1995. http://www.unwomen.org/ /media/headquarters/attachments/ sections/csw/pfa_e_final_web.pdf (accessed 22 Apr 2016).

28. World Health Organization. Roadmap for action, (2014-2019): integrating equity, gender, human rights and social determinants into the work of WHO. Geneva: WHO, 2015.

29. Lee H, Pollitzer E. The Role of Gender-based Innovations for the UN Sustainable Development Goals. 2016. https://www.medscinet.com/ GI/Uploads/SDG_Report_FINAL.Jan13\%20(1).pdf (accessed 22 Apr 2016)

30. Buitendijk S, Maes K. Gendered research and innovation: integrating sex and gender analysis into the research process. Leuven: League of European Research Universities, 2015.

31. Ovseiko PV, Greenhalgh T, Adam P, et al. A global call for action to include gender in research impact assessment. Health Res Policy Syst 2016;14:50.

32. European Commission. Access to healthcare and long-term care. Equal for women and men? Final synthesis report. Luxembourg: Publications Office of the European Union, 2009.

33. Dhruva SS, Bero LA, Redberg RF. Gender bias in studies for Food and Drug Administration premarket approval of cardiovascular devices. Circ Cardiovasc Qual Outcomes 2011;4:165-71.

34. Heidari S, Babor TF, De Castro P, et al. Sex and gender equity in research: rationale for the SAGER guidelines and recommended use. Res Integr Peer Rev 2016;1:2. 